\title{
RESEARCH
}

Open Access

\section{Microendoscopic anterior cervical foraminotomy: a preliminary series of 76 cases}

Mohamed Samir Kabil ${ }^{*}$ a and Walid Abdel-ghany

\begin{abstract}
Background: Anterior cervical foraminotomy represents a relatively recent minimally invasive approach that can potentially preserve the intervertebral disc and thus the functional motion segment.

Objective: This study aims to evaluate the clinical outcome of microendoscopic anterior cervical foraminotomy (MACF) for patients with cervical unilateral radiculopathy due to single level soft disc herniation or hard discosteophyte complex (DOC).
\end{abstract}

Methods: In the period between August 2009 and March 2015, 76 consecutive patients with symptomatic unilateral cervical radiculopathy were included in this study. There were 40 left-sided cervical radiculopathy cases and 36 right-sided; of those, 42 had soft disc fragment herniation, 18 had DOC, 12 had a migrated disc fragment whether cranial or caudal, and four had far lateral (foraminal) disc herniation. In all cases, MACF with root decompression was performed. Cervical magnetic resonance imaging (MRI), computed tomography (CT) scan, and plain X-rays were performed for all patients and then repeated postoperatively. All patients were followed-up for at least a year. Clinical and functional outcomes were assessed using visual analogue scale (VAS) and Odom's criteria.

Results: According to VAS score, there was an improvement in neck pain from 6.4 (range 5-10) to $1.5(1-5)$ and in arm pain from 7.2 (range 6-10) to $1.2(0-4)$ at final follow-up $(P<0.05)$. Functional outcomes according to Odom's criteria were excellent in 59 (78\%) cases, good in ten (13\%), fair in six (8\%), and poor in one (1\%) case. Success of surgery was considered to be achieved in 91\% (excellent + good) of cases. Mean operating time was 81 min, and mean intraoperative blood loss was $21 \mathrm{ml}$. Most significant complications included a dural tear in one case, transient postoperative dysesthesia in six cases, excess bony work resulting in unintended uncinectomy in three cases, fracture of transverse process in one case, unintended near total discectomy in two cases, infective discitis in one case, and persistent radicular pain due to incomplete osteophyte removal in one case.

Conclusions: This preliminary report suggests that MACF yields overall excellent results in selected patients with unilateral cervical radiculopathy. The technique potentially can preserve the functional motion segment, thus patients typically experience immediate postoperative neck mobility and do not need to wear a cervical collar.

Keywords: Anterior cervical foraminotomy, Cervical radiculopathy, Soft disc herniation, Microendoscopic cervical surgery

\footnotetext{
*Correspondence: kabilms@yahoo.com

Department of Neurosurgery, Ain Shams University Hospital, Cairo, Egypt
}

\section{Springer Open}

(c) The Author(s). 2020 Open Access This article is licensed under a Creative Commons Attribution 4.0 International License, which permits use, sharing, adaptation, distribution and reproduction in any medium or format, as long as you give appropriate credit to the original author(s) and the source, provide a link to the Creative Commons licence, and indicate if changes were made. The images or other third party material in this article are included in the article's Creative Commons licence, unless indicated otherwise in a credit line to the material. If material is not included in the article's Creative Commons licence and your intended use is not permitted by statutory regulation or exceeds the permitted use, you will need to obtain permission directly from the copyright holder. To view a copy of this licence, visit http://creativecommons.org/licenses/by/4.0/. 


\section{Introduction}

Cervical radiculopathy is a frequent neurosurgical presenting condition among middle age to elderly populations. Axial neck and arm pain coupled with distal paresthesia within the distribution of compressed nerve root and possible motor weakness are typically the admitting complaints. Sudden onset usually points out to cervical soft disc herniation, whereas insidious onset with progressive radiculopathy conceivably arises from degenerative cervical bony spurs ensuing cervical spondylosis $[1,2]$.

Conservative management for six consecutive months is the usual primary line of management with favorable results. Refractory medical treatment in presence of intractable pain or progressive neurological deficit warrant surgical resolution [3]. Posterior laminectomy that evolved later into a keyhole foraminotomy and anterior decompression with or without fusion are the standard surgical treatment for cervical radiculopathy; each with its advantages and limitations [4]. Posterior approach has the advantage of preserving the spinal motion segment in return for indirect decompression and incapability to access some ventrolateral lesions.

Although, associated with an easier access, yet anterior approach may be considered risky because of the proximity of visceral and neurovascular structures. Additionally, it frequently induces symptomatic adjacent disc disease ending in fusion that subsequently disrupts the functioning motional segment [5].

Jho, in 1996 [5], introduced the microsurgical anterior cervical foraminotomy for management of cervical disc pathologies through uncovertebral joint which comprises eradication of the compressive pathology while preserving the disc and averting necessity for fusion procedure. Excessive post procedural pain and muscle spasm congruent with evolving microendoscopic surgeries originally developed by Smith and Foley [6] prompted employing microendoscopic endoscopy systems for management of cervical radiculopathy [7]. In this report, we share our experience with microendoscopic anterior cervical foraminotomy (MACF) in management of 76 patients having soft disc herniations and degenerative bony osteophytes triggering cervical radiculopathy.

\section{Patients and methods}

This study was conducted by the Department of Neurosurgery of Ain-shams University Hospitals in the period between August 2009 and March 2015. Seventy-six patients (56.6\% men and $43.4 \%$ women) with a median age of 40 years (range 29-67 years) were evaluated for unilateral cervical radiculopathy and subjected to MACF via the anterior approach by the senior author (MK).

Patients were considered for our study upon having the following criteria: (1) unilateral radiating neck and arm pain/numbness attributable to single level soft disc herniation or degenerative uncovertebral osteophytes, for which uninterrupted medical treatment for six consecutive weeks was unresponsive, (except if the pain was severe, the fragment was large, and the patient was willing to proceed to surgery directly or if complications related to root compression have already occurred); (2) cross-sectional (MRI, CT) imaging corroborating diagnosis of soft disc herniation and bone spurs that are congruent with the patients' clinical presentation; and (3) no evidence of cervical instability as demonstrated by dynamic plain radiography. Criteria for exclusion were as follow: (1) multi-level intervertebral pathologies, (2) prior history of cervical spine surgery, and (3) coexistent considerable spondylotic stenosis with resultant myelopathy causing spinal cord compression.

\section{Surgical procedure}

Prior to the procedure, an informed consent was taken from all patients. Patients were situated in supine position with slight neck extension. Under fluoroscopic guidance, about $2 \mathrm{~cm}$ skin incision is made on the symptomatic side between medial two-thirds and lateral onethird of the sternocleidomastoid medial border. Lateral $\mathrm{C}$-arm fluoroscopy is used to confirm the operative level. After incising cervical superficial fascia, visceral structures inclusive of trachea and esophagus are drawn medially while the carotid sheath kept laterally. Dissection of prevertebral fascia while reassuring correct level is performed followed by about $7 \mathrm{~mm}$ transversely incising the medial part of longus colli muscle about 5-6 $\mathrm{mm}$ cranial and caudal to the confinements of intervertebral disc space. Thereafter, the incised part is resected and kept laterally revealing more of the uncinate process (UP) while keeping an eye on the vertebral artery (VA) at its endangered location when operating at the level of C7.

An endoscopic sheath and obturator of the Endospine ${ }^{\circ}$ system (Karl Storz GmbH \& Co., Tuttlingen, Germany) is advanced through the incision targeting UP. The obturator is then removed followed by insertion of an endoscopic insert and endoscope. Fluoroscopy is then repeated to ensure the exact working level and positioning. Thenceforth, the surgical field is a composite of lateral portion of intervertebral disc sandwiched between the lateral parts of cranial and caudal vertebral bodies.

A high-speed drill with a $4 \mathrm{~mm}$ diamond burr is then utilized to drill-out part of the inferiorly UP and the superiorly vertebral junction along with bony spurs on lateral endplate while leaving a thin posterior layer of cortical bone at the lateral wall of UP as a safeguard for the VA. The drilling is continued deeply in the direction of the spinal canal and ipsilateral nerve root. The covering periosteum and any required element of the 
posterior longitudinal ligament are removed using 2-mm straight and angled Kerrison rongeurs to achieve complete decompression of the nerve root. Herniated/ migrated disc fragments are looked for via a micro-hook and further removed using the disc rongeur.

Following that, and before closure is commenced, careful rummage of the intervertebral foramen is done to assure full decompression. This is followed by copious irrigation and hemostasis. The platysma muscle is then reapproximated and skin closure with no drains is then accomplished. Patients are advised for early mobilization, yet with avoidance of intense activity. Cervical collar is not necessary. Potent analgesics are given to minimize postprocedural pain. Post-procedural clinical and radiographic follow-up assessments were employed at 6 months, and 1year interval. The following data were collected: surgical time, blood loss, success rate, length of hospital stay, as well as nature of complications if present (Fig. 1).

\section{Pre- and post-procedural evaluation}

Clinical and functional outcomes were analyzed utilizing visual analogue scale (VAS) for neck and arm pain (score from 0 to 10 where 0 indicates absence of pain and 10 signifies the maximum pain) as well as Odom's criteria where patients are rated from excellent to poor relative to resolution, improvement, persistence, or exaggeration of preoperative presentation. Four surgical results were obtained: (1) excellent (all preoperative symptoms relieved; abnormal findings improved), (2) good (minimal persistence of preoperative symptoms; abnormal findings unchanged or improved), (3) fair (definite relief of some preoperative symptoms; other symptoms unchanged or slightly improved), and (4) poor (symptoms and signs unchanged or exacerbated). Treatment success was interpreted as remarkable symptomatic improvement or resolution (Figs. 2 and 3).

IBM SPSS statistics (V. 24.0, IBM Corp., USA, 2016) was used for data analysis. Data were expressed as median and percentiles for quantitative non-parametric measures in addition to both number and percentage for categorized data. The following tests were done: (1) Wilcoxon signed rank test for comparison between two dependent groups for non-parametric data. (2) Chisquare test to study the association between each two variables or comparison between two independent groups as regards the categorized data. The probability of error at 0.05 was considered significant, while at 0.01 and 0.001 are highly significant.

\section{Results}

Seventy-six patients with male:female ratio equal to $3: 2$ were enrolled for this study. Their age ranged from 29 to 67 years old (median age was 40 years). All cases had cervical radiculopathy (40 cases on the left side, and 36 cases on the right side) while neck pain was encountered in $90.8 \%(n=69)$. Neurological compromise, evident as altered sensation and motor weakness, was seen in 41 (53.9\%) and $34(44.7 \%)$ of the patients respectively.

Preoperative MRI scans elucidated disc abnormalities clearly, where $55.3 \%(n=42)$ of the patients had soft



Fig. 1 Intraoperative endoscopic view during a left sided C6-7 fragmentectomy. a Medial bony boundary. b Microhook. c Disc fragment excision. d Suction 


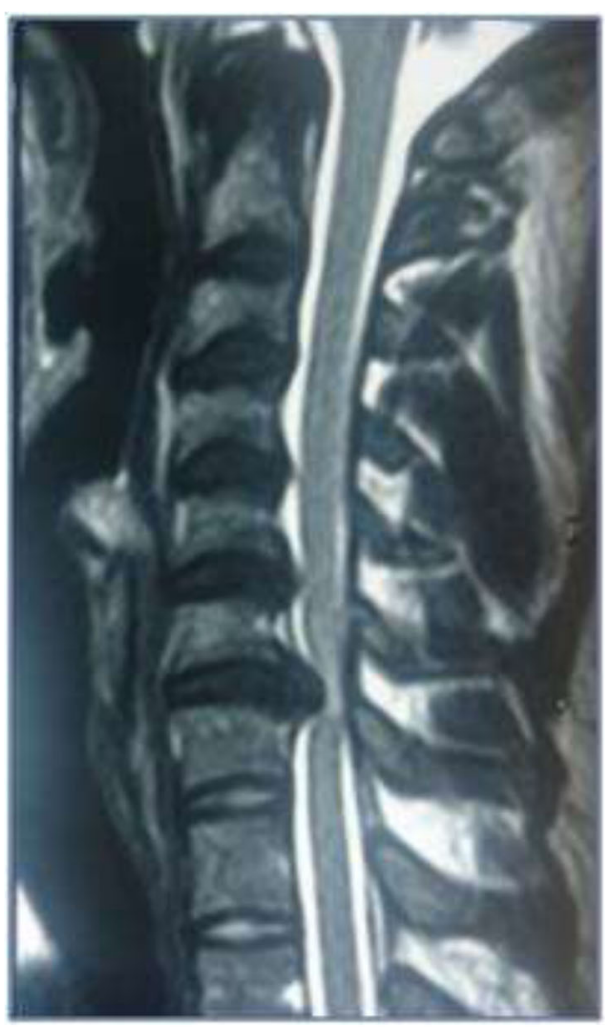

(a)

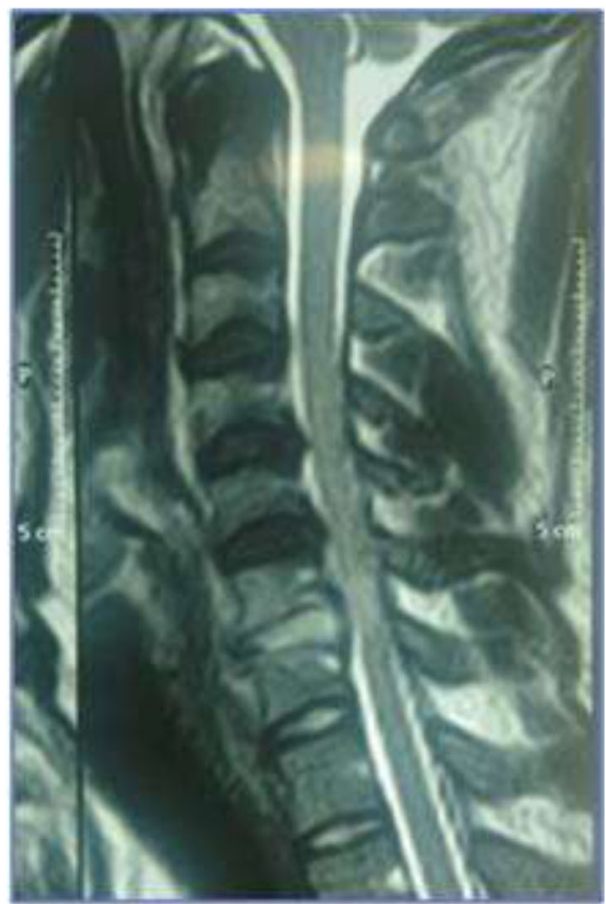

(b)

Fig. 2 a Preoperative sagittal T2-weighted MRI, showing a C6-7 disc prolapse. $\mathbf{b}$ Early postoperative sagittal T2-weighted MRI of same patient

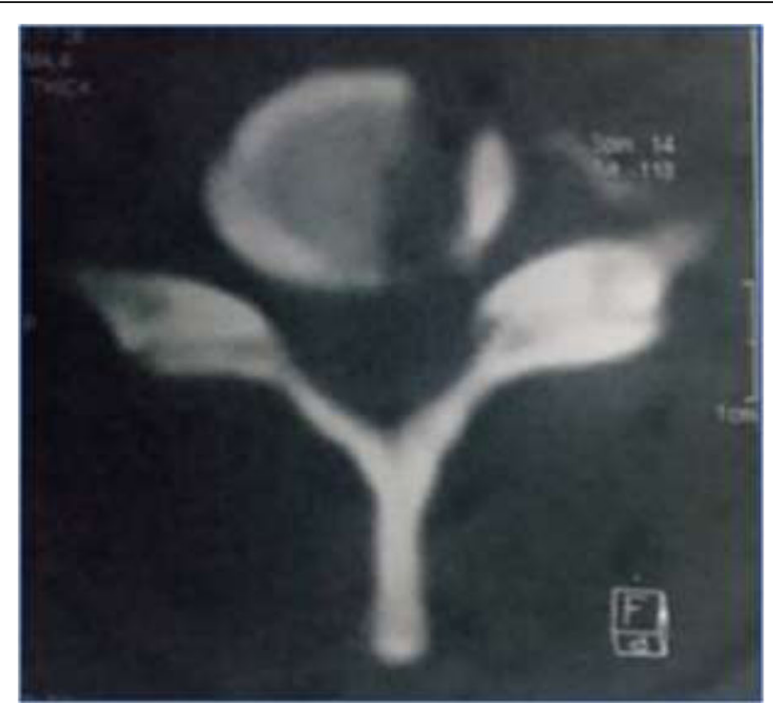

(a)

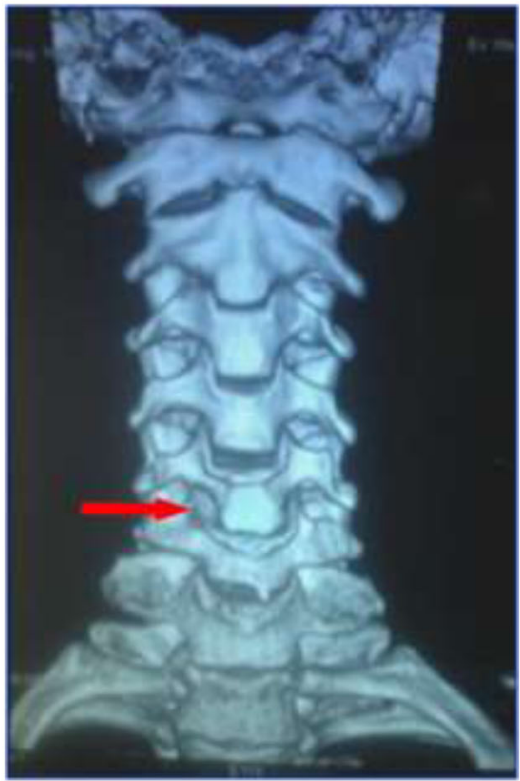

(b)

Fig. 3 a Postoperative axial CT scan showing C5-6 right foraminotomy. b 3D CT scan of same patient

disc fragment herniation, $15.8 \%(n=12)$ demonstrated rostral or caudal migrated disc fragment while far lateral disc herniation was depicted only in four $(5.3 \%)$ of the patients. Spondylotic vertebral bony spurs was obviously noted in 18 (23.7\%) patients on plain radiography and high-resolution CT scans.

Per-level analysis, anterior cervical foraminotomy procedure was performed at $\mathrm{C} 3-\mathrm{C} 4$ in $9.2 \%(n=7), \mathrm{C} 4-\mathrm{C} 5$ in $11.8 \%(n=9)$, C5-C6 in $40.8 \%(n=31)$, C6-C7 in $36.8 \%(n=28)$, and C7-T1 in $1.3 \%(n=1)$. Mean surgical time was $81 \mathrm{~min}$, and mean blood loss during 
surgery was $21 \mathrm{ml}$. The mean hospital stay following cervical foraminotomy was $1.1 \pm 0.6$ days.

The mean follow-up period was 20.3 months (13-56 months). Comparable to preoperative complaints at 6 months and 1 year follow-up, a highly significant decrease of median VAS score for arm pain $(P<0.05)$ was depicted. Descriptive statistics for the improvement between preoperative and 6 month postoperatively shows that among 76 patients; arm pain was improved from 7.2 (range $6-10$ ) to $1.2(0-4)$. No statistical significance difference was noted between 6 and 12 months followup. Similarly, the median VAS scores for neck pain at 6 month improved significantly from 6.4 (range 5-10) to 1.5 (1-5) with stable presentation till last follow-up (Table 1 and Fig. 4).

On evaluation of functional outcome, the overall results were excellent in $77.6 \%(n=59)$ of the patients, good in $13.2 \%(n=10)$, fair in $7.9 \%(n=6)$, and poor in $1.3 \%(n=1)$. Among those with excellent results $(n=$ 59), $11.9 \%$ were treated for cervical pathology at level of $\mathrm{C} 3 / 4,15.3 \%$ at $\mathrm{C} 4 / 5,23.7 \%$ at $\mathrm{C} 6 / 7,1.7 \%$ at $\mathrm{C} 7-\mathrm{T} 1$, while the highest proportion with $47.5 \%(n=28)$ belongs to level C5-C6. Contrariwise, among those showed good, fair, and poor results $(n=10,6,1), 70.0 \%, 100 \%$, $100 \%$ were attained at level of C6-C7. Furthermore, we found a positive highly significant correlation $(P=0.000)$ between functional outcome results and admitting diagnosis where $66.1 \%(n=39)$ of excellent results were attributable to management of soft disc fragment herniation followed by $18.6 \%(n=11)$ as a sequelae of caudal or cranial migrated discs. Among those exhibiting

Table 1 Clinical symptoms attributable to different pathologies at disc levels

\begin{tabular}{ll}
\hline Demographics & Patient percentage (no.) \\
\hline Reoperative symptomatology & \\
Radicular arm pain & $100 \%(n=76)$ \\
Axial neck pain & $90.8 \%(n=69)$ \\
Altered sensation & $53.9 \%(n=41)$ \\
Motor weakness & $44.7(n=34)$ \\
2 Offending pathology & \\
Soft disc fragment herniation & $55.3 \%(n=42)$ \\
Cranial / caudal disc fragments & $15.8 \%(n=12)$ \\
Foraminal herniation & $5.3 \%(n=4)$ \\
Osteophytic spurs & $23.7 \%(n=18)$ \\
3 Disc level & \\
C3-C4 & $9.2 \%(n=7)$ \\
C4-C5 & $11.8 \%(n=9)$ \\
C5-C6 & $40.8 \%(n=31)$ \\
C6-C7 & $36.8(n=28)$ \\
C7-T1 & $1.3 \%(n=1)$ \\
\hline
\end{tabular}

good results, $60 \%$ were to osteophytes comparable to $30 \%$, and $10 \%$ soft fragment herniation and disc migration. Osteophytes treatment lead up to $100 \%$ of fair and poor results (Tables 2 and 3 and Figs. 5 and 6).

A total of $15(19.73 \%)$ peri-operative complications were encountered. Dural tear with secondary minute intraoperative CSF leakage took place in one $(1.3 \%)$ patient; nonetheless, it was successfully repaired leaving no chronic consequences. Inadvertent uncinectomy and transverse process fracture occurred in three $(3.95 \%)$ and one $(1.3 \%)$ patient respectively; however, they were insignificant necessitating no further intervention. Six (7.9\%) patients experienced self-limiting postoperative dysesthesia, whereas unintended near total discectomy occurred in two cases. Postoperative cervical MRI revealed $1.3 \%(n=1)$ case of infective discitis that was managed conservatively with culture-specific IV antibiotics along with spinal immobilization and yielded favorable outcome. Another case of technical failure continued to have post-procedural radicular pain owing to residual uncovertebral osteophyte at C6-7 evident on high resolution $\mathrm{CT}$ for which patient underwent revision surgery. Neither morbidity nor reoperation attributable to postoperative spinal instability took place in our study.

\section{Discussion}

The hallmarks of cervical radiculopathy reported to occur in 1.79/1.000 person-years in the USA as stated by Schoenfeld et al. [8] are axial neck pain and radiating arm pain with potential sensory deficit or motor weakness as well as diminished reflexes resultant from impingement of cervical nerve root/s via arthritic osseous spurs or herniated soft intervertebral disc material $[8,9]$. Interplay of variable factors such as increase vascular permeability with intraneural edema escorted by release of inflammatory mediators like substance $\mathrm{P}$ could provoke the evolution of radicular pain [10].

Spondylotic degenerative stenosis comprises about $78 \%$ of cervical radiculopathies while only $22 \%$ are attributable to acute disc herniations [11] that were at odds with our results yielding spondylotic vertebral spurs in only $23.7 \%$ of patients comparable to disc pathologies alternating between $55.3 \%$ with soft herniation, $15.8 \%$ with disc fragment migration, while far lateral disc herniation was depicted only in 5.3\%.

Harboring the utmost soft tissue contrast resolution as well as greatest capability to elucidate the nerve till exiting the neural foramen, cervical MRI is considered the gold standard neuroradiological preoperative technique in evaluation of cervical radiculopathy [12]. However, Van de Kelft and van Vyve [13] claimed that an axial MRI cuts demonstrate low specificity for foraminal lesions. Moreover; demarcation between soft disc 


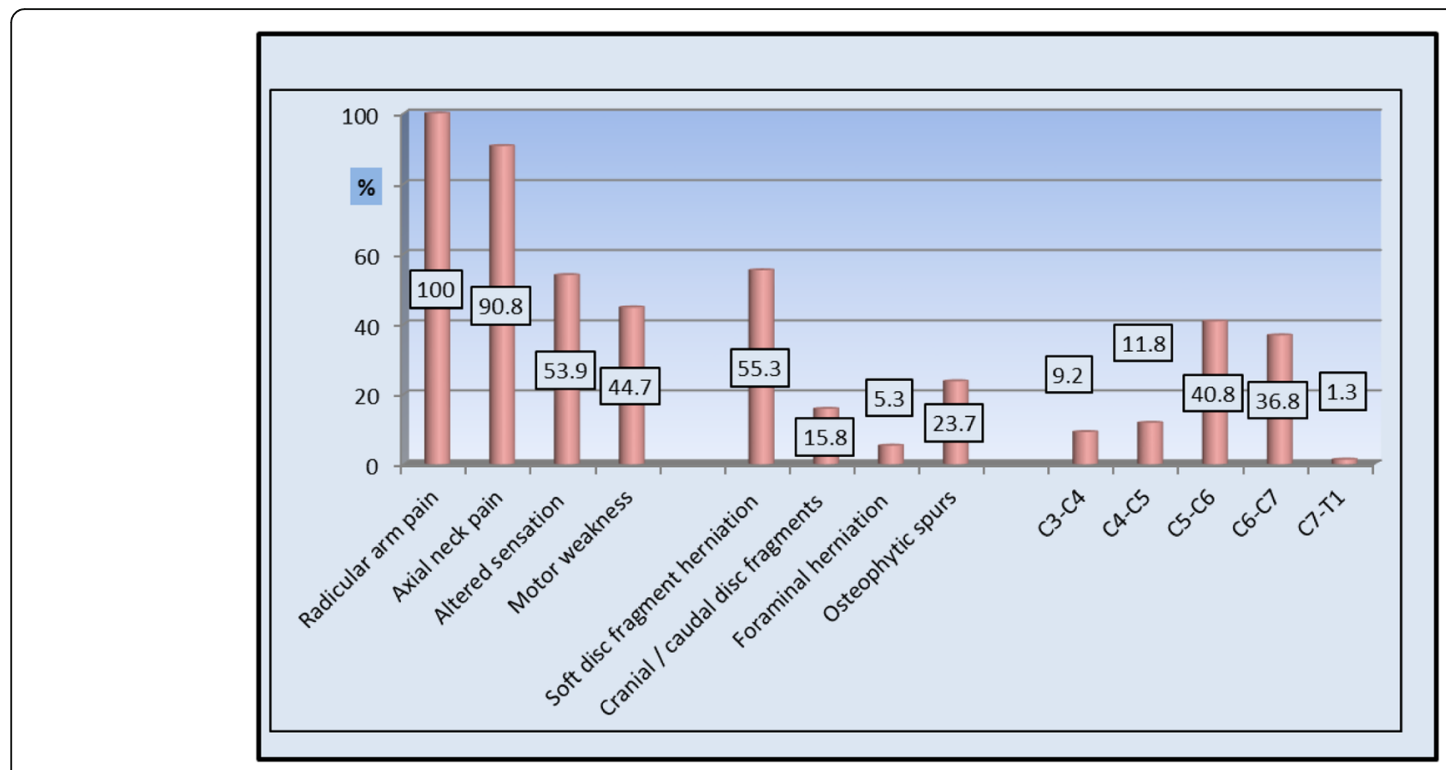

Fig. 4 Clinical symptoms attributable to different pathologies at disc levels

herniation and osteophytic spurs is not always clear. Here, comes the imperative role of anteroposterior (AP) and lateral plain radiography illustrating foraminal bony osteophytes as well as cervical CT, the most sensitive modality to interrogate the spinal bony elements, that whenever coupled with myelography can clearly pursue the course of the nerve root $[12,14]$.

In the present study, preliminary assessment with static and dynamic planar imaging was done firstly to delineate cervical alignment and elucidate gross osseous pathologies to be followed by CT and MRI imaging to confirm nerve root compromise via arthritic bony spurs or herniated soft disc material respectively. Exempting

Table 2 Odom's category in relation to disc level

\begin{tabular}{|c|c|c|c|c|c|c|}
\hline & & & \multicolumn{4}{|c|}{ Odom category } \\
\hline & & & Excellent & Fair & Good & Poor \\
\hline \multirow[t]{10}{*}{ Level operated } & $\mathrm{C} 3-\mathrm{C} 4$ & Count & 7 & 0 & 0 & 0 \\
\hline & & $\%$ & $11.9 \%$ & $0.0 \%$ & $0.0 \%$ & $0.0 \%$ \\
\hline & $\mathrm{C} 4-\mathrm{C} 5$ & Count & 9 & 0 & 0 & 0 \\
\hline & & $\%$ & $15.3 \%$ & $0.0 \%$ & $0.0 \%$ & $0.0 \%$ \\
\hline & $\mathrm{C} 5-\mathrm{C} 6$ & Count & 28 & 0 & 3 & 0 \\
\hline & & $\%$ & $47.5 \%$ & $0.0 \%$ & $30.0 \%$ & $0.0 \%$ \\
\hline & $\mathrm{C} 6-\mathrm{C} 7$ & Count & 14 & 6 & 7 & 1 \\
\hline & & $\%$ & $23.7 \%$ & $100.0 \%$ & $70.0 \%$ & $100.0 \%$ \\
\hline & $\mathrm{C} 7-\mathrm{T} 1$ & Count & 1 & 0 & 0 & 0 \\
\hline & & $\%$ & $1.7 \%$ & $0.0 \%$ & $0.0 \%$ & $0.0 \%$ \\
\hline Chi-square tests & Value & & $P$ & & & \\
\hline Pearson chi-square & 21.999 & & .038 & & & \\
\hline
\end{tabular}

one case with incomplete osteophyte removal, the postoperative MRI scans demonstrated sufficient decompression with neither osteophytes remnant nor herniated/ migrated soft disc material.

The natural course of degenerative cervical radiculopathy is favorable and the majority $(75-90 \%)$ will eventually improve with non-surgical management inclusive of medications, cervical collar, physical therapy, and selective nerve blocks [15-17]. Patients with compressive radiculopathy with persistent radicular pain or progressive sensorineural deficit or motor weakness after 6 months of consecutive medical treatment are candidates for surgical intervention. Cervical radiculopathy used to be surgically treated with either anterior or posterior operative approaches [18, 19].

Spurling and Scoville [20] were the first to introduce posterior cervical spine surgery followed by multiple retrospective studies affirming the efficacy of posterior foraminotomy in the management of cervical spondylotic stenosis [21-25]. Besides carrying no risk of injury to visceral structures or carotid sheath, several other advantages have been related to the posterior approaches entailing preservation of cervical motion segment, reduction of adjacent segment degeneration, and the capability to visualize the affected nerve root directly enabling removal of constricting fibrous tissues [1, 2, 26]. Many studies portrayed success rate following posterior foraminotomy which escalates between 90 and 96\% reported by Scoville et al. [21] and Henderson et al. [23] in a retrospective study with 736 candidates and Collias et al. [22] to $97 \%$ found by Zeidman and Ducker [24] till 100\% relief of radicular pain and motor power amelioration yielded by Aldrich 1990 [25]. 
Table 3 Odom's category in relation to offending pathology

\begin{tabular}{|c|c|c|c|c|c|c|c|}
\hline & & & \multicolumn{4}{|c|}{ Odom category } & \multirow[t]{2}{*}{ Total } \\
\hline & & & Excellent & Fair & Good & Poor & \\
\hline \multirow[t]{8}{*}{ Cause cervical radiculopathy } & Disc migration & Count & 11 & 0 & 1 & 0 & 12 \\
\hline & & $\%$ & $18.6 \%$ & $0.0 \%$ & $10.0 \%$ & $0.0 \%$ & $15.8 \%$ \\
\hline & Foraminal disc herniation & Count & 4 & 0 & 0 & 0 & 4 \\
\hline & & $\%$ & $6.8 \%$ & $0.0 \%$ & $0.0 \%$ & $0.0 \%$ & $5.3 \%$ \\
\hline & Osteophytes & Count & 5 & 6 & 6 & 1 & 18 \\
\hline & & $\%$ & $8.5 \%$ & $100.0 \%$ & $60.0 \%$ & $100.0 \%$ & $23.7 \%$ \\
\hline & Soft disc fragment herniation & Count & 39 & 0 & 3 & 0 & 42 \\
\hline & & $\%$ & $66.1 \%$ & $0.0 \%$ & $30.0 \%$ & $0.0 \%$ & $55.3 \%$ \\
\hline \multirow[t]{2}{*}{ Total } & & Count & 59 & 6 & 10 & 1 & 76 \\
\hline & & $\%$ & $100.0 \%$ & $100.0 \%$ & $100.0 \%$ & $100.0 \%$ & $100.0 \%$ \\
\hline Chi-square tests & & Value & $P$ & & & & \\
\hline Pearson chi-square & & 37.597 & .000 & & & & \\
\hline
\end{tabular}

Contrariwise, same level degeneration with secondary kyphosis and considerable post-procedural axial neck pain are two frequent sequelae in view of partial resection of facet joint and muscle stripping in open surgical procedures respectively [27, 28]. Cervical instability could arise if more than $50 \%$ of facet joint is resected which drove Chang et al. [29] to develop a novel alternative procedure through inclinatory decompression with minute resection of facet joint without bone fusion under title posterior cervical inclinatory foraminotomy. Over and above, it is comprehensible that posterior procedures are less preferable than anterior approach since the offending pathology is frequently frontal to the nerve root rendering surgical positioning troublesome with high risk of epidural bleeding [30].

Originally described in 1995 and 1958 when Robinson and Smith [31] as well as Cloward [32] successfully consummated direct decompression of the offending spondylotic osteophyte and soft disc fragment through anterior cervical discectomy with results comparable to the posterior approach. In 1968, Verbeist [33] introduced a complex anterolateral approach to the cervical spine embracing lateral displacement of the VA and anterior cervical compression with and without fusion. It aimed for management of various pathologies such as VA and nerve roots compression via bony spurs and radiculopathy attributable to lateral disc herniations. Transuncodiscal approach leaving VA untouched was outlined by Hakuba [34] for myeloradiculopathy and VA insufficiency yielding favorable results with no significant post-procedural displacement in the group with noninterbody fusion.

In a technique similar to that described by Verbeist, five patients with foraminal disc herniation proved with CT underwent discoforaminotomy in the study reported by Lesoin et al. [35], where total exploration of nerve root throughout its entire course from radiculomedullary junction till the extra-foraminal part was possible

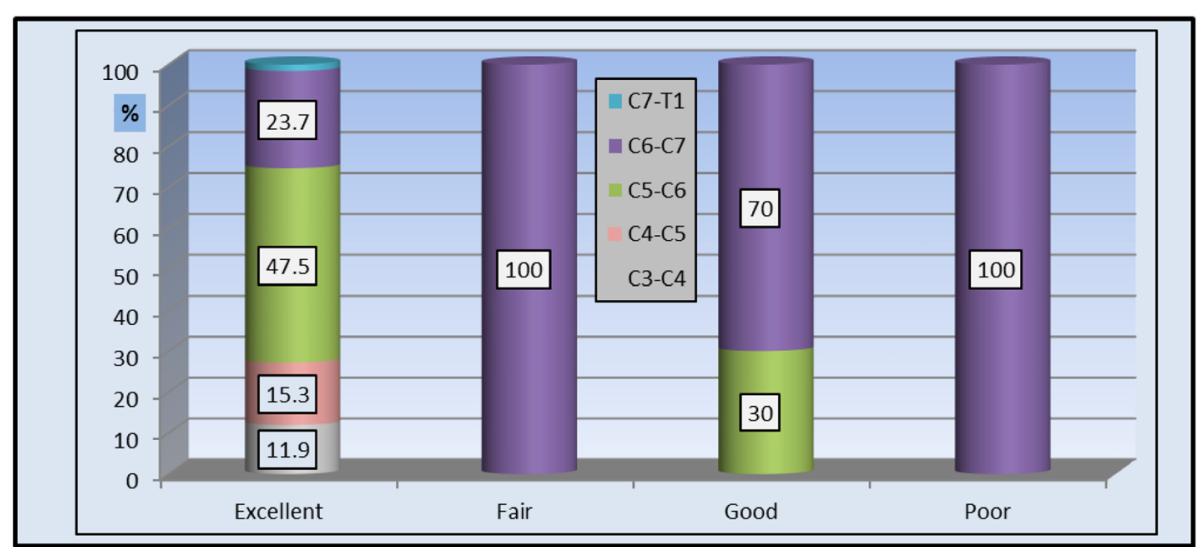

Fig. 5 Odom's category in relation to disc level 


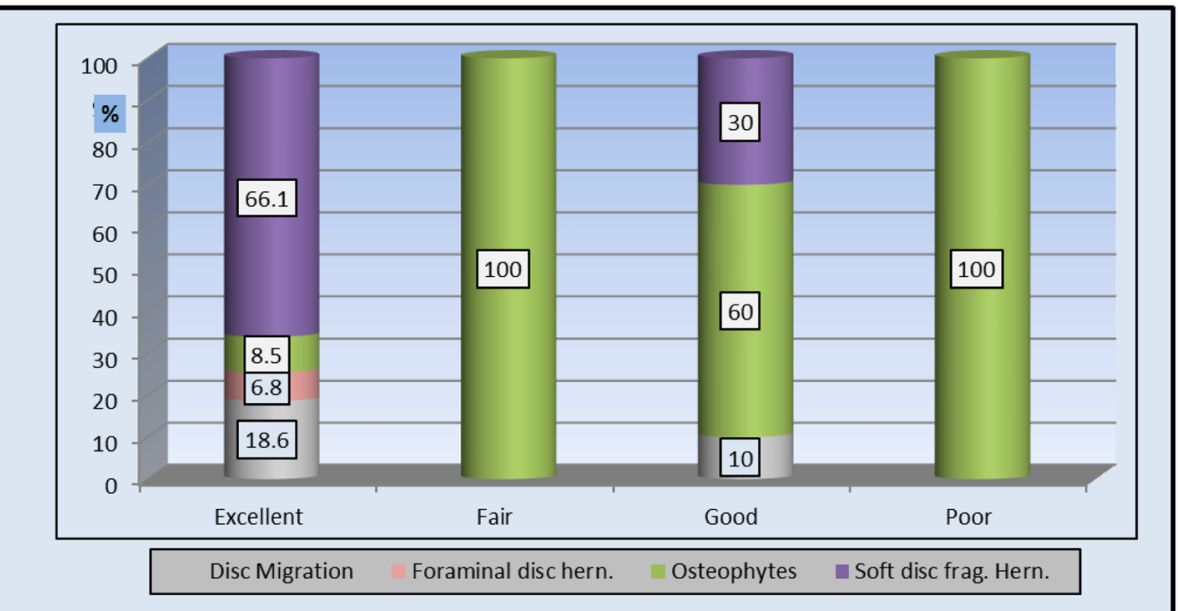

Fig. 6 Odom's category in relation to offending pathology

and achieved good results. However, all previous reports had inherent disadvantages of loss of disc height with subsequent mobile segment fusion that predispose to further progression of degenerative changes at adjacent disc levels. Similarly, discectomy cases with bone fusion harbor the risk of pseudoarthrosis and bone graft-related complication.

Thereafter, anterior cervical fractional interspace decompression (ACFID) was proposed by Snyder and Bernhardt [36] as an adequate method for neuroforaminal decompression without the risk of segmental collapse and spontaneous fusion in 63 patients with radiculopathy caused by soft and hard discs. However, $36 \%$ of the patients were graded as poor and fair outcome following the procedure adding to $5 \%$ who experienced persistent nerve root compression as an ACFID failure which may be explained by incomplete removal of uncovertebral joint. Moreover, it still entails removal of one-third of the intervertebral disc.

Jho [5] and Johnson et al. [37] presented an advantageous technique of anterior cervical foraminotomy with resection of UP, lateral segment of the superiorly vertebral end plate, and the intervertebral disc. The technique is unrivaled in that it preserved the cervical functional segment obviating necessity of fusion procedure. On the other side, medial exposure of VA with its complications is still a pre-requisite [4]. Saringer et al. [38], in their lower vertebral trans-corporeal approach for uncoforaminotomy technique, left a thin cortical piece of bone at the lateral wall of the UP as a mark to avoid VA exposure.

Incessant advancements within the field of microendoscopic surgery made it a feasible attractive management strategy for wide variety of pathologies as herniated disc materials and spinal canal stenosis. Small surgical incision and smooth tissue dissection while achieving comparable results to the open surgery are among the advantages $[39,40]$. Our technique resemble that of Saringer et al. [7] who firstly incorporated the advantages of the modified anterior cervical foraminotomy technique with microendoscopic endoscopy system inclusive of minimal exposure and improved intraoperative visualization for functional disc-sparing decompressive surgery in 16 patients with cervical radiculopathy. Saringer et al. [7] reported resolution of the radicular pain in $94 \%$ of the patients while being improved in $6 \%$. Normal motor power was regained in $84 \%$ of cases comparable to $80 \%$ which exhibited normalization of sensory deficit.

Out of 104 patients treated for cervical radiculopathy in Jho et al.'s [41] series, success rate was $99 \%$ with excellent outcome in $79.8 \%$. These results mirror those attained within our study. Success rate of $91 \%$ alternating between excellent results in $77.6 \%$ and good results in $13.2 \%$ was achieved. Level C5-C6 possessed approximately half $(47.5 \%)$ of the excellent outcome results while the whole fair and poor results were evidently noted at C6-C7. Moreover, soft disc fragment herniation showed the most favorable response with $66.1 \%(n=39)$ of excellent results dissimilar from degenerative osteophytes which constituted all of the fair and poor results.

Analogous to our results, in the series reported by Koc et al. [42], 19 patients were followed for 23 months and the outcome was evaluated using Odom's criteria and the VAS, revealing excellent outcome in $78.9 \%$. At 6 months follow-up, our patients reported an overall highly significant decrease of median VAS score for arm pain from 7.2 to 1.2 comparable to preoperative complaints. Further, $44.7 \%$ of patients who had motor weakness in the preoperative assessment restored their normal power dislike from $80.5 \%$ out of 41 patients with altered sensations. In a similar study [43], the mean VAS score for arm and neck pain reduced by 6.9 and 4.0 
respectively. Sensorineural deficit and motor weakness each improved by 3.8 .

Fully endoscopic anterior microforaminotomy technique presented in Yadav et al. [44] achieved good results with less mean operative time $(110 \mathrm{~min})$ and blood loss $(30 \mathrm{ml})$ that was comparable to other anterior decompressive procedure and paralleling ours where the mean intra-procedural EBL was $21 \mathrm{ml}$. In our study, the mean operating time was much less about 81 min which may be explained by previous experience of the senior author (MK) in preparing and handling microendoscopic environments in other setting of lumbar canal stenosis.

Following microsurgical or open anterior cervical foraminotomy, the most common complication reported by Song et al. [45] respectively were dural tears $(1.07 \%$, $0.27 \%)$, nerve root injury $(0.8 \%, 1.4 \%)$, and infection $(0.54 \%, 0.40 \%)$. In our study, we had complication in $19.73 \%$ of the cases which varied between $5.26 \%(n=4)$ osseous complication, $3.94 \%(n=3)$ soft disc compromise, 9.21\% $(n=7)$ neural impairment, and one case $1.31 \%$ of dural tear with minute CSF leakage that was repaired intra-procedurally leaving no chronic consequences. Fessler and Khoo [46] had three cases; one with partial thickness dural violation and two with small CSF leakage that were resolved spontaneously within 2-3 days without long-term sequelae. Adamson [47] in his report illustrating microendoscopic laminoforaminotomy, yet through posterior approach, had two cases of asymptomatic dural tears that were managed via gel foam. Saringer et al. [7] nominated epidural venous bleeding as inevitable incident with microendoscopic approach deriving from the epidural veins is almost inevitable with the endoscopic anterior approach since venous plexi surround both thecal sac and nerve root; however, they are easily managed by cauterization. Suction drain being left for $48 \mathrm{~h}$ in all patients as a routine restrained popping up of epidural hematomas in the current study.

Jho [41] reported one case of infectious discitis; that despite adequate antibiotic treatment, the patient developed mild kyphosis sequent to spontaneous bone fusion. In our study, post-procedural fever and severe back pain notably seen in one patient along with imaging features inclusive of disc space low signal on T1W and high signal on T2W with hyper intensity on DWI in parallel with enhancement of vertebral end plates and surrounding soft tissue on postoperative cervical MRI with contrast points out to diagnosis of infective discitis. Early diagnosis and prompt treatment with culture-specific IV antibiotics while patient being advised for spinal immobilization drove total resolution 1 month after. Inadvertent near total discectomy was manifested in two of our cases with loss of disc height, unfortunately followed by complicated spontaneous fusion; however, patients experienced no symptoms recurrence till the last follow-up that does not necessitate another decompressive surgery.

Postoperative neural-related complications configured as transient dysesthesia were observed in $7.89 \%$ of cases; however, dysesthesia was mild and resolved gradually till vanishing at the last follow-up visit. One study [41] reported post-procedural transient self-resolving hemiparesis possibly caused by prolonged neck extension while others mentioned minimal residual discomfort or slight transient exacerbation of neurological symptoms leaving no permanent deficit $[34,48]$. In line with Jho [41] and Johnson [37], another case continued to have persistent radicular pain in the distribution of $\mathrm{C6}-7$ following the procedure. High-resolution cervical CT revealed a residual uncovertebral osteophyte for which patient underwent another decompressive surgery with remarkable improvement of median VAS score for arm pain from 8 to 2 .

In this series, $1.3 \%$ and $3.95 \%$ of cases experienced inadvertent asymptomatic postoperative uncinectomy and fracture of transverse process that were detected on control cervical computed tomography and healed spontaneously necessitating no further intervention. Although long-term follow-up data is absolutely necessary and was absent in this study, no reoperation attributable to postoperative cervical instability took place in our study.

In line with Choi et al. [4] and dissimilar with Jho [41], Johnson [37], and Tumialán et al. [49], neither Horner's syndrome nor transient or persistent superior/recurrent laryngeal nerve paresis were noted in the current study.

\section{Conclusions}

Microendoscopic anterior cervical foraminotomy is a minimally invasive relatively novel procedure that in this study has effectively ameliorated patients with unilateral cervical radiculopathy through direct eradication of the etiological element whether spondylotic degenerative stenosis or soft disc herniation/migration. The aim is to achieve total decompression of the involved nerve root while potentially maintaining cervical functional segment with less post-procedural pain and faster recovery.

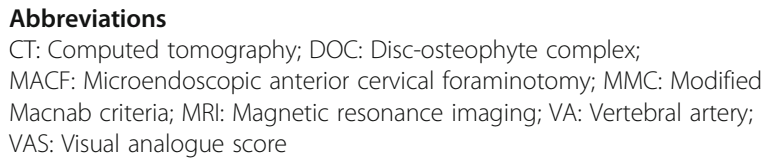

Consent for participation

All patients signed an informed consent for the procedure and possible outcomes.

Authors' contributions

Mohamed Kabil, main author, performed all of procedures, clinical assessment, follow-up of patients, and is responsible for the study concept 
and design. Walid Abdel-ghany contributed into follow-up of patients, collection of results, statistics, and final editing. All authors read and approved the final manuscript.

\section{Funding}

Nothing to disclose.

\section{Availability of data and materials}

This is a limited group preliminary study of a relatively novel surgical procedure. All data was recorded by the author and readers can find the supporting data within the study.

\section{Ethics approval and consent to participate}

Retrospective ethics approval was obtained from the Faculty of Ain Shams University, General Surgery Department, research ethics committee, where the committee approved the study protocol form the ethical point of view.

\section{Consent for publication}

This study reported no personal data for any patients; informed consents were obtained for all patients included in this study for publishing of results. None of the patient involved in this study had declined publication of study results.

\section{Competing interests}

The authors declare that they have no competing interests.

\section{Received: 24 April 2018 Accepted: 29 April 2020}

Published online: 11 May 2020

\section{References}

1. Terai $H$, Suzuki A, Toyoda $H$, Yasuda $H$, et al. Tandem keyhole foraminotomy in the treatment of cervical radiculopathy: retrospective review of 35 cases. J Orthop Surg Res. 2014;9:38.

2. Grieve J, Kitchen N, Moore A, Marsh H. Results of posterior cervical foraminotomy for treatment of cervical spondylitic radiculopathy. $\mathrm{Br} J$ Neurosurg. 2000;14(1):40-3.

3. Faldini C, Leonetti D, Nanni M, Di Martino A, et al. Cervical disc herniation and cervical spondylosis surgically treated by Cloward procedure: a 10-yearminimum follow-up study. J Orthopaed Traumatol. 2010;11:99-103.

4. Choi G, Lee S, Bhanot A, Chae Y, et al. Modified trans corporeal anterior cervical microforaminotomy for cervical radiculopathy: a technical note and early results. Eur Spine J. 2007;16:1387-93.

5. Jho HD. Microsurgical anterior cervical foraminotomy for radiculopathy: a new approach to cervical disc herniation. J Neurosurg. 1996:84:155-60.

6. Smith M, Foley K. Micro endoscopic discectomy. Tech Neurosurg. 1997;3: 301-7.

7. Saringer W., Reddy B., Huhmann I., Regatschnig R., et al. Endoscopic anterior cervical foraminotomy for unilateral radiculopathy: anatomical morphometric analysis and preliminary clinical experience. J Neurosurg (Spine 2)2003; 98:171-180.

8. Schoenfeld AJ, George AA, Bader JO, Caram PM Jr. Incidence and epidemiology of cervical radiculopathy in the United States military: 2000 to 2009. J Spinal Disord Tech. 2012;25(1):17-22

9. Eubanks J. Cervical radiculopathy: non-operative management of neck pain and radicular symptoms. Am Fam Physician. 2010;81(1):33-40.

10. Polston DW. Cervical radiculopathy. Neurol Clin. 2007;25(2):373-85.

11. Radhakrishnan K, Litchy WJ, O'Fallon WM, Kurland LT. Epidemiology of cervical radiculopathy. A population-based study from rochester, Minnesota, 1976 through. Brain 1994. 1990:117(Pt 2):325-35.

12. Caridi J, Pumberger $M$, Hughes A. Cervical radiculopathy: a review. HSSJ. 2011;7:265-72

13. Van de Kelft E, van Vyve M. Diagnostic imaging algorithm for cervical soft disc herniation. J Neurol Neurosurg Psychiatry. 1994;57:724-8.

14. Kim KT, Kim YB. Cervical radiculopathy due to cervical degenerative diseases: anatomy, diagnosis and treatment. J Korean Neuro Soc. 2010;48(6): 473-9. https://doi.org/10.3340/jkns.2010.48.6.473.

15. Sampath P, Bendebba M, Davis JD, Ducker T. Outcome in patients with cervical radiculopathy. Prospective, multicenter study with independent clinical review. Spine. 1999;24(6):591-7.

16. Lees F, Turner J. Natural history and prognosis of cervical spondylosis. $\mathrm{Br}$ Med J. 1963;2(35):1607-10.
17. Lestini W, Wiesel S. The pathogenesis of cervical spondylosis. Clin Orthop Relat Res. 1989:69-93.

18. Storm P, Chou D, Tamargo RJ. Surgical management of cervical and lumbosacral radiculopathies: Indications and outcomes. Phys Med Rehabil Clin N Am. 2002;13:735-59.

19. Saal JS, Saal J, Yurth EF. Non-operative management of herniated cervical intervertebral disc with radiculopathy. Spine. 1996;21:1877-83.

20. Spurling R, Scoville W. Lateral rupture of the cervical intervertebral disc: a common cause of shoulder and arm pain. Surg Gyencol Obstet. 1994;78: 350-8.

21. Scoville WB, Dohrmann G, Corkill G. Late results of cervical disc surgery. J Neurosurg. 1976;45(2):203-10.

22. Collias J. and Roberts MP. Posterior operations for cervical disc herniation and spondylitic myelopathy IN Schmidek HH, Sweet WH, eds, Operative Neurosurgical Technique s. Philadelphia: W. B. Saunders, 1995:1805 \pm 16.

23. Henderson C., Hennesy R., Shuey H. and Shackelford G. Posterior-lateral foraminotomy as an exclusive operative technique for cervical radiculopathy-a review of 864 consecutively operated cases. Neurosurgery 1983: 13(5): 504-512.

24. Zeidman S, Ducker TB. Posterior cervical laminoforaminotomy for radiculopathy: review of 172 cases. Neurosurgery. 1993;33(3):356-62

25. Aldrich F. Posterolateral micro discectomy for cervical mono radiculopathy caused by posterolateral soft cervical disc sequestration. J Neurosurg. 1990; 72:370-7.

26. Jagannathan J, Sherman J, Szabo T, Shaffrey C, Jane J. The posterior cervical foraminotomy in the treatment of cervical disc/osteophyte disease: a singlesurgeon experience with a minimum of 5 years' clinical and radiographic follow-up. J Neurosurg Spine. 2009:10:347-56.

27. Fehlings M, Gray R. Posterior cervical foraminotomy for the treatment of cervical radiculopathy. J neurosurg Spine. 2009;10:343-4.

28. Hosono N, Yonenobu K, Ono K. Neck and shoulder pain after laminoplasty. A notable complication. Spine. 1996;21:1969-73.

29. Chang J., Park H. and Choi S. Posterior cervical inclinatory foraminotomy for spondylotic radiculopathy preliminary. J Korean neurosurgery 2011; Soc 49: 308-313.

30. Jho H. Failed anterior cervical foraminotomy (Editorial). J Neurosurg (Spine 2) $2003 ; 98: 121-125$

31. Robinson R, Smith G. Anterolateral cervical disc removal and interbody fusion for cervical disc syndrome. Bull Johns Hopkins Hosp. 1955;96:223-4.

32. Cloward RB. The anterior approach for removal of ruptured cervical disks. J Neurosurg. 1958;15:602-14

33. Verbeist $H$. A lateral approach to the cervical spine: technique and indications. J Neurosurg. 1968:28:191-203.

34. Hakub A. Trans-unco-discal approach. A combined anterior and lateral approach to cervical discs. J Neurosurg. 1976;45:284-91.

35. LeSoin F, Biondi A, Jomin M. Foraminal cervical herniated disc treated by anterior discoforaminotomy. Neurosurgery. 1987;21:334-8.

36. Snyder G, Bernhardt M. Anterior cervical fractional interspace decompression for treatment of cervical radiculopathy. A review of the first 66 cases. Clin Orthop. 1989;246:92-9.

37. Johnson J, Filler A, McBride D, Batzdorf U. Anterior cervical foraminotomy for unilateral radicular disease. SPINE. 2000;25(8):905-9.

38. Saringer W, Nobauer I, Reddy M, et al. Microsurgical anterior cervical foraminotomy (Unco foraminotomy) for unilateral radiculopathy: clinical results of a new technique. Acta Neurochir. 2002;144:685-94.

39. Minamide A, Yoshida M, Yamada H, Nakagawa Y, et al. Clinical outcomes of microendoscopic decompression surgery for cervical myelopathy. Eur Spine J. 2010;19:487-93.

40. Dahdaleh N, Wong A, Smith Z, Wong R, et al. Microendoscopic decompression for cervical spondylotic Myelopathy. Neurosurg Focus. 2013; 35(1):E8.

41. Jho HD, Kim WK, Kim MH. Anterior microforaminotomy for treatment of cervical radiculopathy: part 1—disc-preserving "functional cervical disc surgery". Neurosurgery. 2002:51(Suppl 5):S46-53.

42. Koc R, Menku A, Tucer B, Gocmez C, Akdemir H. Anterior cervical foraminotomy for unilateral spondylotic radiculopathy. Minim Invasive Neurosurg. 2004:47:186-9.

43. White B, Buxton N, Fitzgerald JJ. Anterior cervical foraminotomy for cervical radiculopathy. Br J Neurosurg. 2007;21:370-4.

44. Yadav $Y$, Parihar $V$, Ratre $S$, Kher $Y$. Endoscopic anterior decompression in cervical disc disease. Neurol India. 2014;62(4):417-25. 
45. Song Z, Zhang Z, Hao J, Shen J, et al. Microsurgery or open cervical foraminotomy for cervical radiculopathy? International Orthopedics (SICOT): A systematic review; 2016.

46. Fessler R, Khoo L. Minimally invasive cervical micro endoscopic

Foraminotomy: an initial clinical experience. Neurosurgery. 2002;51(Suppl 2): 37-45.

47. Adamson T. Micro endoscopic posterior cervical laminoforaminotomy for unilateral radiculopathy: results of a new technique in 100 cases. Neurosurg 2001; (Spine 1) 95:51.

48. Lunsford LD, Bissonette DJ, Jannetta PJ, Sheptak PE, Zorub DS. Anterior surgery for cervical disc disease. Part 1: treatment of lateral cervical disc herniation in 253 cases. J Neurosurg. 1980;53(1):1-11. https://doi.org/10. 3171/jns.1980.53.1.0001.

49. Tumialán L, Ponton R, Gluf W. Management of unilateral cervical radiculopathy in the military: the cost effectiveness of posterior cervical foraminotomy compared with anterior cervical discectomy and fusion. Neurosurg Focus. 2010;28(5):E17.

\section{Publisher's Note}

Springer Nature remains neutral with regard to jurisdictional claims in published maps and institutional affiliations.

\section{Submit your manuscript to a SpringerOpen ${ }^{\circ}$ journal and benefit from:}

- Convenient online submission

- Rigorous peer review

- Open access: articles freely available online

High visibility within the field

- Retaining the copyright to your article

Submit your next manuscript at $\boldsymbol{\nabla}$ springeropen.com 